\title{
MEAN THEORETIC APPROACH TO A FURTHER EXTENSION OF GRAND FURUTA INEQUALITY
}

\author{
MASATOSHi ITO AND EIZABURO KAMEI
}

Abstract. Very recently, Furuta has shown a further extension of grand Furuta inequality. In this paper, we obtain a more precise and clear expression of Furuta's extension by considering a mean theoretic proof of grand Furuta inequality. Moreover, we get a variant of Furuta's extension by scrutinizing the former argument.

Mathematics subject classification (2010): 47A63, 47A64.

Keywords and phrases: Positive operators, operator mean, Furuta inequality and grand Furuta inequality.

Acknowledgement. The authors would like to express their cordial thanks to the referee for his kind comments.

\section{REFERENCES}

[1] T. Ando And F. HiaI, Log majorization and complementary Golden-Thompson type inequalities, Linear Algebra Appl., 197, 198 (1994), 113-131.

[2] M. FuJII, Furuta's inequality and its mean theoretic approach, J. Operator Theory, 23 (1990), 67-72.

[3] M.FuJiI, T.Furuta AND E.KAMEI, Furuta's inequality and its application to Ando's theorem, Linear Algebra Appl., 179 (1993), 161-169.

[4] M. FujiI, M. Ito, E. Kamei And A. Matsumoto, Operator inequalities related to Ando-Hiai inequality, to appear in Sci. Math. Jpn.

[5] M. FujiI And E. KameI, Mean theoretic approach to the grand Furuta inequality, Proc. Amer. Math. Soc., 124 (1996), 2751-2756.

[6] M. Fujil AND E. KAMEI, Ando-Hiai inequality and Furuta inequality, Linear Algebra Appl., 416 (2006), 541-545.

[7] M. Fujil, A. Matsumoto And R. NaKamoto, A short proof of the best possibility for the grand Furuta inequality, J. Inequal. Appl., 4 (1999), 339-344.

[8] T. Furuta, $A \geqslant B \geqslant 0$ assures $\left(B^{r} A^{p} B^{r}\right)^{1 / q} \geqslant B^{(p+2 r) / q}$ for $r \geqslant 0, p \geqslant 0, q \geqslant 1$ with $(1+2 r) q \geqslant$ $p+2 r$, Proc. Amer. Math. Soc., 101 (1987), 85-88.

[9] T. FurUtA, An elementary proof of an order preserving inequality, Proc. Japan Acad. Ser. A Math. Sci., 65 (1989), 126.

[10] T. FURUTA, Extension of the Furuta inequality and Ando-Hiai log-majorization, Linear Algebra Appl., 219 (1995), 139-155.

[11] T. FuRUTA, Simplified proof of an order preserving operator inequality, Proc. Japan Acad. Ser. A Math. Sci., 74 (1998), 114.

[12] T. FURUTA, Invitation to Linear Operators, Taylor \& Francis, London, 2001.

[13] T. FuRUTA, Monotonicity of order preserving operator functions, Linear Algebra Appl., 428 (2008), 1072-1082.

[14] T. FURUTA, Further extension of an order preserving operator inequality, J. Math. Inequal., 2 (2008), $465-472$.

[15] T. FuRUTA, Operator function associated with an order preserving operator inequality, J. Math. Inequal., 3 (2009), 21-29. 
[16] M. ITO AND E. KAMEI, A complement to monotonicity of generalized Furuta-type operator functions, Linear Algebra Appl., 430 (2009), 544-546.

[17] M. ITO AND E. KAMEI, Ando-Hiai inequality and a generalized Furuta-type operator function, Sci. Math. Jpn., 70 (2009), 43-52.

[18] E. KAMEI, A satellite to Furuta's inequality, Math. Japon., 33 (1988), 883-886.

[19] F. Kubo And T. Ando, Means of positive linear operators, Math. Ann., 246 (1980), 205-224.

[20] K. Tanahashi, Best possibility of the Furuta inequality, Proc. Amer. Math. Soc., 124 (1996), 141146.

[21] K. Tanahashi, The best possibility of the grand Furuta inequality, Proc. Amer. Math. Soc., 128 (2000), 511-519.

[22] T. YAMAZAKI, Simplified proof of Tanahashi's result on the best possibility of generalized Furuta inequality, Math. Inequal. Appl., 2 (1999), 473-477.

[23] J. YuAN AND Z. GaO, Classified construction of generalized Furuta type operator functions, Math. Inequal. Appl., 11 (2008), 189-202. 